\title{
INFORMAÇÃO, MEMÓRIA INSTITUCIONAL E PRODUÇÃO ACADÊMICA: O LEGADO DA UFES NA WEB OF SCIENCE (2009-2018)
}

http://dx.doi.org/10.5902/2318133839273

\author{
Rosa da Penha Ferreira da Costa ${ }^{1}$ \\ Marcelo Calderari Miguel ${ }^{2}$
}

\begin{abstract}
Resumo
Neste texto apresenta-se o resultado de análise do percurso da Universidade Federal do Espírito Santo - Ufes - por meio de indicadores bibliométricos, em torno de artigos científicos dos autores associados a instituição e representados na Web of Science - WoS -, no período de 2009 a 2018. Utilizou-se para a análise a abordagem quantitativa da medição da produção científica institucional na WoS; a situação dos norteadores bibliométricos para compor um diagnóstico por meio da amostragem de 6.650 itens documentais desdobrados em autores, países e revistas. O referencial empírico abrangeu 339 dos artigos envolvendo a instituição e que se encontram na base de dados, sendo analisado por meio dos softwares NetDraw, Ucinet 6.0 e Vantage Point 5.0. Notouse que a produção da Ufes na base de dados pesquisada aumentou de 308 artigos em 2009, para 1.078 em 2018, com taxa média de crescimento anual de 15,19\%. Em termos gerais percebeu-se que, nesse percurso de dez anos, a entidade se fortaleceu; que os relacionamentos sociais expressaram a existência de uma rede de coautoria ainda bastante fragmentada; que a maior parte da produção associada a instituição está registrada em inglês e em periódicos de impacto; que dezoito artigos recentes foram altamente citados ( $>100)$, todos em inglês, sendo os mesmo em colaboração internacional e publicado em periódicos de impacto.
\end{abstract}

Palavras-chave: imagem organizacional; bibliometria; redes de colaboração científica; universidades brasileiras.

\section{INFORMATION, INSTITUTIONAL MEMORY AND ACADEMIC PRODUCTION: THE UFES LEGACY IN THE WEB OF SCIENCE (2009-2018)}

\section{Abstract}

This text presents the result of the analysis of the path of the Universidade Federal do Espírito Santo - Ufes - through bibliometric indicators, around scientific articles of the authors associated with the institution and represented in the Web of Science - WoS -, in the period of 2009. 2018. The quantitative approach to measuring institutional scientific production at WoS was used for analysis; the situation of bibliometric guides to compose a diagnosis by sampling 6,650 documentary items deployed in authors, countries and journals. The empirical reference covered 339 of the articles involving the institution and found in the database, being analyzed using NetDraw, Ucinet 6.0 and Vantage Point 5.0 software. Ufes production in the database searched increased from 308 articles in 2009 to 1.078 in 2018, with an average annual growth rate of $15.19 \%$. In general terms it was noticed that in this ten-year course, the entity has strengthened itself; that social relationships expressed the existence of a still very fragmented co-authoring

\footnotetext{
${ }^{1}$ Universidade Federal do Espírito Santo, Brasil. E-mail: rosapenha2012@gmail.com.

2 Universidade Federal do Espírito Santo, Brasil. E-mail: marcelocalderari@yahoo.com.br.
}

\begin{tabular}{ll|lll} 
Regae: Rev. Gest. Aval. Educ. & Santa Maria & v. 8 & n. 17 & Pub. contínua 2019
\end{tabular} 
network; whereas most of the institution's associated production is recorded in English and in impact journals; eighteen recent articles were highly cited (>100), all in English, the same in international collaboration and published in impact journals.

Key-words: organizational image; bibliometrics; scientific collaboration networks; Brazilian universities.

\section{Introdução}

ponto categórico do saber está em delinear uma perspectiva para a maturidade e o futuro, pois o universo do conhecimento é multidisciplinar, não há unanimidade e, sim, 'ilhas de competência', nas quais a ciência se expande (Schwartzman, 2001). No período moderno o tradicional modelo de universidade passou por diferentes pressões para se atualizar, um exemplo de embate e mudança advém da Argentina, com a Reforma de Córdoba, que em 1918 trouxe à tona a preocupação de se levar a universidade até a população, ocasião em que os "jovens reivindicavam uma universidade atenta à ciência, aos problemas nacionais e que fosse ao encontro da população [...] Daí o manifesto, clamando outras universidades a incorporar a pauta da autonomia universitária" (Sugimoto, 2018, p. 1).

Sendo assim, há que se destacar que ciência materializa-se na produção de documentos, os quais carecem de canais formais e informais para publicação e o proeminente meio de comunicação da ciência em praticamente todas as campos, ainda é o periódico científico, por coligar, em um único meio, artigos de distintas instituições e autorias (Brambilla; Stumpf, 2012). Considera-se que a visibilidade da revista científica se constitui na contrapartida do compartilhamento dos êxitos e descobertas com as implicações relevantes na admissão pelos pares, provocando o pertencimento a uma comunidade científica (Barba, 2003).

Percebe-se a importância das comunicações das pesquisas acadêmicas e também há que se destacar a responsabilidade ética e complexidade de medir qualidade em qualquer âmbito (Brambilla; Stumpf, 2012). Avaliar a dimensão da ciência produzida em uma universidade é possível na esfera da comunicação científica e, para tal escopo, utiliza-se técnicas quantitativas e métricas de ranqueamento implícitas em princípios basilares da bibliometria.

Brambilla e Stumpf (2012) afirmam que os indicadores são instrumentos que, se bem empregados e dentro dos limites estabelecidos pela técnica quantitativa de avaliação da ciência, podem funcionar como um filtro de controle e qualidade, dando acesso ao movimento ciência aberta e orientando a gerência das políticas de gestão institucional. Assim, motivados pelos argumentos dessas pesquisadoras e pelas ações pelos 65 anos da Ufes, busca-se analisar os artigos publicados por autores vinculados à Universidade Federal do Espírito Santo, entre 2009-2018, e disponíveis na base de dados Web of Science - WoS.

A justificativa para isso baseia-se na inexistência de um estudo que exponha a representatividade da produção científica da Ufes. A utilização da WoS apoia-se no fato da base científica ser uma das mais utilizadas para citação e proporciona um enfoque aprumado de publicações que zelam pela qualidade. 
As pesquisas sobre a produtividade de uma IES evidência os elos e o prestígio entre os autores, ampara comportamentos e tendências evolutivas nas áreas do conhecimento e compõem importantes fontes de informação para a gestão de políticas públicas endereçadas à ciência, tecnologia e inovações. Além disso, sendo a escola superior um importante espaço de atividade científica, pode-se considerar representativo um estudo descritivo e avaliativo a respeito de algum aspecto relacionado ao desempenho da IES. Brambilla e Stumpf (2012) esclarecem que o exame das informações sobre as publicações geradas pelos pesquisadores no papel de seu posto investigativo, tem o intuito de refletir a natureza, a dinâmica e a magnitude da literatura (re)criada.

As questões que permearam o estudo partem da avaliação da ciência produzida na Ufes e visam à observar quais as características dessa produção científica e que áreas do conhecimento estão representadas na base de dados, estimadas pelas medidas de atividade e qual a visibilidade da produção científica de pesquisadores da Ufes, em termos de artigos publicados em periódicos representados em uma base de dados internacional, estimada pelas medidas bibliométricas. Com isso buscou-se estabelecer um breve diagnóstico da produção científica da Ufes, em termos dos artigos publicados em periódicos nacionais e estrangeiros, representados na base de dados WoS.

Portanto, obter medidas a partir da análise estatística dos resultados científicos cumpre, em parte, a finalidade de mensurar e assinalar os impactos dos esforços da política científica e tecnológica em propagar a pesquisa, a extensão e o papel social resultante dos investimentos auferidos a estrutura de uma organização. Elencar métrica não é apenas tornar manifesta e analisável a pesquisa, mas também envolve o uso incentivado de indicadores bibliométricos em prol da construção das redes colaborativas e da comunicação de experiências exitosas a serem disseminadas para sustentabilidade e continuidade da CT\&I.

\section{Memórias e percurso: 65 anos escrevendo histórias}

O histórico sobre a origem e desenvolvimento das universidades é abordado por Bellotto (1989). Essa autora afirma que sua criação remonta à Baixa Idade Média, no século 12, quando as atividades relacionadas ao ensino superior deixaram de ocorrer apenas nos espaços religiosos, tais como mosteiros. Com uma nova forma de organização do trabalho, o surgimento das corporações, grupos de pessoas passaram a buscar maior aprendizado, recorrendo a mestres aptos a conceder títulos para os que se capacitavam profissionalmente. Dessa forma passou a haver uma união entre mestres e alunos, que buscaram defender seus direitos profissionais, daí surgindo o termo universitas, a partir da formação dessas corporações.

Segundo Rossato (2005 apud Bohrer et al, 2008) a denominação [corporação] que era outorgada à universidade, Universidade de Paris, se formou em 1150 com o título de Estudos Gerais, em que a Teologia era a mais importante de todas. Já no século 13 Bohrer et al (2008) reporta que a imagem da organização está consolidada com a formação da Corporação dos Mestres Parisienses (1262) ou Universitas Magistrorum et Scholarium: tal local de estudos recebe alunos de todas as nações, tendo então o reconhecimento oficial da mais alta autoridade civil e religiosa. 
Para Belloto (1989) no declinar da época imperial romana salva-se o saber e a cultura clássica e as universidades aparecem em várias regiões da Europa: Bolonha, Oxford, Paris, Salermo, Cambridge, Montpellier, Pádua, Salamanca, Coimbra. Bellotto (1989) aponta, ainda, o crescente fortalecimento da universidade, inicialmente pela lição e do debate, evoluindo na atuação da formação de profissionais e na utilização de novas maneiras de exame e reflexão.

No século 17 consolidava-se a nova forma corporativa da educação superior e "a universidade nascia, pois, [...] dentro da fermentação provocada pelo início da anteposição entre as tendências ruralizantes do sistema feudal e as tendências libertárias do novo mundo urbano" (Bellotto, 2014b, p. 66). Como consequência, ainda, segundo Bellotto (2014b), houve maior senso de responsabilidade e de iniciativa, o que leva a autora a afirmar que as universidades foram organizadas aos poucos, baseando-se no sistema corporativo e não foram fundadas, como dito por alguns autores.

$\mathrm{Na}$ ldade Moderna passaram a melhor definir suas funções, porém ainda voltadas para o ensino, sem, contudo, preocuparem-se com a sociedade na qual estavam inseridas. E apenas no século 19, com a reformulação da Universidade de Berlim, deixou de ser um espaço apenas de transmissão de conhecimentos, passando então a contribuir teórica e metodologicamente com a Ciência, transmitindo o que era pesquisado, e dessa forma "se forjaram as novas universidades do século $20 \mathrm{em}$ todo o mundo" (Bellotto, 1989, p. 18).

Como coube à IES ser o locus da ciência, ela teve que prover seu corpus científico, elevando o ensino superior a um padrão mais avançado, voltado à formação pósgraduada de pesquisadores. No Brasil o desenvolvimento da pós-graduação começou a partir dos anos 1950, quando as universidades qualificaram-se para a pesquisa (Brambilla; Stumpf, 2012). Foi criado um sistema de bolsas de estudo, incentivando a formação de professores e pesquisadores no exterior, pela Capes, destinando os recursos para fomento por meio do CNPq. Atualmente, a pós-graduação é responsável pela maior parte da pesquisa realizada no país, que envolve uma vasta gama de intergentes.

Todavia, ressalta-se que a criação de um sistema de ensino superior no Brasil não acompanhou o seu surgimento na América Latina, trazido pelos espanhóis no século 16, com a criação de universidades no México, Argentina, Chile, etc. No Brasil, de acordo com Cunha (2000, p, 162), a primeira instituição de ensino superior a adquirir o status de 'universidade foi Universidade Federal do Rio de Janeiro, no ano de 1920.

A criação da Ufes foi pensada entre os anos de 1951 e 1952, pelo então governador Jones dos Santos Neves. Esse governador criou várias faculdades isoladas, sendo que em 1953, o então criado Conselho de Ensino Superior, fez um anteprojeto de lei criando a instituição de ensino, aprovado em abril de 1954 na Assembleia Legislativa e sancionada em 5 de maio do mesmo ano, pela lei n. 806. Apesar de ter sido fundada em 5 de maio de 1954, como uma instituição estadual, a federalização foi proposta em 1960 pelo presidente da República Juscelino Kubitschek, que em 1961 sancionou sua criação como unidade federal. Com a lei federal n. 3.868, de 30 de janeiro de 1961, a Ufes passou a 
constituir-se da: Faculdade de Direito, Escola Politécnica, Faculdade de Ciências Econômicas, Escola de Belas Artes, Faculdade de Odontologia, Faculdade de Filosofia, Ciências e Letras, Faculdade de Medicina e Escola de Educação Física (Ufes, 2014).

Inicialmente a universidade passou por muitas dificuldades, tais como instalações físicas inadequadas, situação funcional instável dos professores e a falta de regulamentação das faculdades e institutos (Borgo, 1995). A federalização não trouxe a resolução dos problemas: em 1962 o professor Jair Etienne Dessaune, indicado pelo MEC para responder provisoriamente pela Reitoria, teve que instalar o gabinete no térreo de sua casa, no centro de Vitória (Ufes, 2014).

No ano de 1966 obteve-se, do governo federal, a desapropriação da área o início das obras de construção de sua Sede em Goiabeiras. Em 1968, pela lei federal n. 5.540/68, teve início o processo de reestruturação do ensino superior no Brasil, sendo que, a partir dessa reestruturação, foram extintas as antigas faculdades de escolas da Ufes, dando lugar aos oito centros universitários e seus respectivos departamentos acadêmicos (Borgo, 1995).

Durante a década de 1970 novas alterações ocorreram na estrutura, com a criação do primeiro mestrado, de quatro sub-reitorias, a construção dos campi de Goiabeiras e Maruípe, além de um grande avanço para a educação capixaba, pela interiorização da universidade, que passou a funcionar também nas cidades de Alegre, São José do Calçado, São Mateus e Nova Venécia (Borgo, 1995).

Nas décadas seguintes continuou se desenvolvendo, sendo que na década de 1980 foram criadas duas novas sub-reitorias: Extensão e de Pesquisa e Pós-Graduação, concluiu-se as obras da Biblioteca Central, do Restaurante Universitário e do Núcleo de Processamento de Dados. Na década de 1990 foram criados novos programas de pósgraduação, aumentando a capacidade de pesquisa, sendo que no ano de 1993 atingiu-se o número de 500 alunos matriculados na pós-graduação e em 1994 sediou-se a 46ª Reunião Anual da Sociedade Brasileira para o Progresso da Ciência - SBPC -, na qual comparecem aproximadamente 21 mil participantes, com um total de 1600 trabalhos apresentados.

Ainda nessa década a estrutura da Ufes passou por grandes alterações, tais como: as sub-reitorias são transformadas em Pró-Reitoras, foram criadas a Prefeitura Universitária, a Ouvidoria, as Secretarias de Assuntos Comunitários, de Comunicação e Divulgação, de Produção e Difusão Cultural, servindo de modelo para demais universidades federais do Brasil. Já no ano de 2000 foi realizado, no campus de Goiabeiras, o primeiro Seminário e Feira de Informação Profissional, que atraiu cerca de 25 mil pessoas. Nesse mesmo ano houve um número recorde de candidatos inscritos ao vestibular: 331.515 pessoas. Houve um aumento na titulação dos docentes e nos projetos de extensão. Foram lançadas novas publicações, além de diversas outras ações. Porém, uma conquista ganhou destaque: a criação do primeiro curso à distância, sendo que a Ufes torna-se modelo no Brasil, nesta modalidade, com a criação do Núcleo de Educação Aberta e a Distância, atual Secretaria de Educação a Distância. 
O Projeto de Reestruturação e Expansão das Universidades - Reuni - permitiu a ampliação de vagas, a criação de novos cursos e o aumento no quadro de servidores. Com isso também aumentam os números de programas de extensão e ampliam-se as pesquisas, havendo então uma alteração na estrutura da Universidade.

A estrutura da Ufes envolve quatro campi universitários - Goiabeiras, Maruípe, São Mateus e Alegre -, com uma área territorial total de 4,3 milhões de metros quadrados. Sua infraestrutura física global é de 292 mil metros quadrados de área construída. Oferece 103 cursos de graduação presencial, com um total de 5.004 vagas anuais. Na pósgraduação possui 47 cursos de mestrado acadêmico, nove de mestrado profissional e 26 de doutorado. Há 19.997 estudantes matriculados na graduação presencial, 3.174na pósgraduação.

Sua estrutura administrativa organiza-se da seguinte maneira: Reitoria, sete PróReitorias: de Administração; de Extensão; de Gestão de Pessoas, de Assuntos Estudantis e Cidadania; de Graduação; de Pesquisa e Pós-Graduação; e de Planejamento e Desenvolvimento Institucional.

Há o Departamento de Administração dos Órgãos Colegiados Superiores, setor encarregado de assistir administrativamente o funcionamento dos conselhos superiores da universidade: o Universitário; o de Ensino, Pesquisa e Extensão e o de Curadores. Também vinculada à administração central, há a Superintendência de Cultura e Comunicação, na qual há as Secretarias de Cultura, Secretaria de Comunicação e Secretaria Administrativa, sendo que vinculados a Secretaria de Cultura estão: a Editora, o Coral e os espaços culturais: Galeria Espaço Universitário, Cine Metrópolis, Teatro Universitário, Livraria. Na Secretaria de Comunicação há a Assessoria de Imprensa, a Seção de Jornalismo, a Seção de Divulgação Científica, o Núcleo de Produção de Conteúdo Institucional, a Divisão de Publicidade e os veículos públicos de comunicação: a Rádio Universitária 104,7 FM e a TV UFES. Além das seguintes secretarias: Secretaria de Ensino a Distância, Secretaria de Relações Internacionais, Secretaria de Avaliação Institucional.

Ainda vinculados à administração central há sete órgãos suplementares: o Sistema Integrado de Bibliotecas da Universidade Federal do Espírito Santo, o Hospital Universitário Cassiano Antônio Moraes, o Instituto de Inovação Tecnológica, o Instituto de Odontologia da Ufes, o Instituto de Tecnologia da Ufes, o Núcleo de Tecnologia da Informação, a Prefeitura Universitária e a Ouvidoria Geral.

As suas unidades acadêmico-administrativas são compostas por dez centros de ensino, nos quais estão distribuídos seus cursos de graduação e pós-graduação, bem como os diversos núcleos e laboratórios de ensino: no campus de Goiabeiras estão os Centro de Artes, o Centro de Ciências Exatas, o Centro de Ciências Humanas e Naturais, - Centro de Ciências Jurídicas e Econômicas, o Centro de Educação, o Centro de Educação Física e Desportos e o Centro Tecnológico. O Centro de Ciências da Saúde localiza-se no campus de Maruípe, o Centro de Ciências Agrárias em Alegre e Jerônimo Monteiro. Em São Mateus o Centro Universitário Norte do Espírito Santo.

Cada centro de ensino tem um diretor, um vice-diretor e um Conselho Departamental, cujos mandados têm a duração de quatro anos para a Direção e de dois anos para os cargos de representação no Conselho Departamental. Também nos centros 
estão localizadas as unidades de ensino, pesquisa e extensão: os departamentos e colegiados de graduação e coordenação de programas de pós-graduação, além dos laboratórios de ensino específicos para cada curso e laboratórios de informática.

Segundo o planejamento estratégico, a Ufes tem como missão "gerar avanços científicos, tecnológicos, artísticos e culturais, por meio do ensino, da pesquisa e da extensão", para dessa forma, produzir e socializar "conhecimento para formar cidadãos com capacidade de implementar soluções que promovam o desenvolvimento sustentável" (Ufes, 2012, p. 9).

Atuando em todas as áreas do saber, têm as seguintes finalidades estatutárias:

Estimular a criação cultural e o desenvolvimento do espírito científico e do pensamento reflexivo; formar diplomados nas diferentes áreas de conhecimento, aptos para a inserção em setores profissionais, para a participação no desenvolvimento da sociedade brasileira e para colaborar na sua formação contínua; incentivar o trabalho de pesquisa e investigação científica, visando ao desenvolvimento da ciência e da tecnologia e da criação e difusão da cultura, e, desse modo, desenvolver o entendimento do homem e do meio em que vive; promover a divulgação de conhecimentos culturais, científicos e técnicos que constituem patrimônio da humanidade e comunicar o saber através do ensino, de publicações ou de outras formas de comunicação; suscitar o desejo permanente de aperfeiçoamento cultural e profissional e possibilitar a correspondente concretização, integrando os conhecimentos que vão sendo adquiridos numa estrutura intelectual sistematizadora do conhecimento de cada geração; estimular o conhecimento dos problemas do mundo presente, em particular os nacionais e regionais, prestar serviços especializados à comunidade e estabelecer com esta uma relação de reciprocidade; promover a extensão, aberta à participação da população, visando à difusão das conquistas e benefícios resultantes da criação cultural e das pesquisas científica e tecnológica geradas na Instituição. (Ufes, 2012, p. 19)

Após completar 65 anos em 2019, a Ufes foi idealizada e continua direcionando esforços à concretização de ações e atividades que procuram assegurar sua missão, finalidades, objetivos, visão e valores. Há cinco objetivos estratégicos.

Quadro 1 -

Objetivos estratégicos da Ufes.

\begin{tabular}{|c|l|}
\hline \multicolumn{2}{|c|}{ Alinhamento organizacional } \\
\hline Ensino & $\begin{array}{l}\text { "Expandir, fortalecer e integrar os ensinos de graduação e pós- } \\
\text { graduação, assegurando a excelência acadêmica, para formar cidadãos } \\
\text { capazes de propor e implementar soluções para as demandas da } \\
\text { sociedade". }\end{array}$ \\
\hline Pesquisa & $\begin{array}{l}\text { "Realizar pesquisas em todas as áreas do saber, buscando a excelência } \\
\text { e expressando o compromisso com o desenvolvimento sustentável". }\end{array}$ \\
\hline Extensão & $\begin{array}{l}\text { "Ampliar a relação da Universidade com a sociedade, desenvolvendo } \\
\text { processos educativos, culturais e científicos, articulados com o ensino, a } \\
\text { pesquisa, voltados à solução de questões locais, regionais e nacionais". }\end{array}$ \\
\hline
\end{tabular}




\begin{tabular}{|c|l|}
\hline Assistência & $\begin{array}{l}\text { "Prestar melhores serviços à sociedade, integrando-se ao ensino, à } \\
\text { pesquisa e à extensão, contribuindo para o atendimento de } \\
\text { necessidades das comunidades interna e externa". }\end{array}$ \\
\hline Gestão & $\begin{array}{l}\text { "Promover mecanismos de gestão para viabilizarem e potencializarem } \\
\text { as atividades de ensino, pesquisa e extensão e assistência de forma } \\
\text { eficiente, eficaz e transparente". }\end{array}$ \\
\hline
\end{tabular}

Fonte: Ufes (2012).

Nesse contexto a Ufes busca ser reconhecida como instituição pública multicampi no Espírito Santo, de excelência nacional em ensino, pesquisa e extensão, com vistas a consolidar "a sua atuação de forma integrada com a sociedade e de forma comprometida com o desenvolvimento sustentável". Seus valores fundamentais são: comprometimento e zelo com a instituição; defesa da universidade gratuita como bem público; busca permanente da excelência no ensino, na pesquisa, na extensão e na gestão; atuação calcada nos princípios da ética, democracia e transparência; respeito à justiça, à equidade social, à liberdade de pensamento e de expressão; compromisso com a coletividade, a pluralidade, a individualidade e a diversidade étnica e cultural; responsabilidade social e interlocução e parceria com a sociedade; preservação e valorização da vida; gestão participativa (Ufes, 2012).

\section{Procedimentos metodológicos}

Nesta pesquisa avaliou-se, no detalhe, uma parte da produção científica da Ufes pelos artigos representados na base de dados WoS. Embora não seja um estudo exaustivo, pois se sabe que muitos periódicos brasileiros não aparecem na base, pode dar uma dimensão do resultado, uma vez que a WoS tem abrangência e cobertura internacional. Por outro lado, a base tem ampliado, significativamente, o número de periódicos e, consequentemente, o número de artigos indexados. Outro fator relevante é o aumento do período de cobertura das revistas, podendo-se afirmar, nesse sentido, que a visibilidade da pesquisa brasileira deve aumentar com essa evolução.

Neste contexto, contempla-se que a bibliometria representa uma técnica de análise utilizada para mensurar a produção científica e Urbizagastegui e Restrepo-Arango (2017) relatam que há um crescimento na literatura acadêmica internacional e nacional de estudos que versam sobre a bibliometria.

Araújo et al. (2017) reportam que a bibliometria é uma instrumento de cálculo e análise quantitativa do estado da arte de uma área do conhecimento científico, valendo da métrica de textos científicos publicados em periódicos e ou eventos científicos. Destacase que a bibliometria é alicerçada por leis, como a Lei de Lotka: produtividade dos autores; a Lei de Price: elite dos autores; a Lei de Bradford: produtividade dos periódicos científicos; e Lei de Zipf: frequência das palavras - e fatores de ranqueamento.

Assim, optou-se por recuperar esses dados na base WoS que foi produzida pelo Institute for Scientific Information - ISI - e atualmente é do grupo Thomson Reuters. Ela está disponível desde 1997, têm abrangência internacional e contém informações bibliográficas e citações de aproximadamente 40 milhões de artigos publicados a partir de 
1945 em mais de 230 disciplinas. Além disso, a WoS oferece registros bibliográficos padronizados, dando a possibilidade de trabalhar com o software Vantage Point, que auxilia na contagem, padronização e organização dos dados.

Foi consultado o JCR para identificar o FI das publicações. Atribuiu-se a contagem de um artigo a cada autor, conforme a metodologia utilizada em outros estudos bibliométricos (Barba, 2003; Zimba; Mueller, 2004; Vanz; Stumpf, 2010). Em relação à série temporal foi selecionado o período 2009-2018, por permitir dotar os resultados de estabilidade e detectar possíveis mudanças na atividade científica no decurso de dez anos.

A coleta dos dados foi realizada entre maio e junho de 2019. A partir do campo address da base, foram selecionados artigos com, pelo menos, um autor vinculado à Ufes, do período 2009-2018, sendo os registros organizados no software MS Excel $\AA^{\circledR}$ advindo da busca na WoS nos seguintes parâmetros.

a) Selecione uma base de dados: 'Principal Coleção do Web of Science';

b) Pesquisa Básica: "Universidade Federal do Espírito Santo";

c) Pesquisa por 'Organização-aprimorada';

d) Tempo estipulado: tempos de anos personalizado '2009-2018';

e) Resultados: 6.654 (na Principal Coleção do Web of Science).

Os dados foram tratados e quantificados utilizando-se o software bibliométrico Vantage Point para gerar uma matriz de coocorrência de instituições autoras das publicações. A matriz foi processada nos softwares de análise e representação de redes Ucinet e NetDraw, resultando na rede de colaboradores em publicações ilustrada em nuvem de interações.

As limitações relativas ao tratamento de dados dizem respeito às restrições impostas pelo uso de indicadores bibliométricos para medir a ciência produzida em uma instituição. A coleta de dados envolveu busca e recuperação dos registros bibliográficos da WoS periódicos indexados nessa base de dados mostram-se mais representativos da atividade científica - em formato '.txt', que é reconhecido pelo software de tratamento bibliométrico utilizado, o Vantage Point. Foi, então, composta a primeira amostra com 6.654 artigos para análise da atividade institucional. Já para atingir o objetivo do diagnóstico utilizou-se diferentes técnicas estatísticas, como segue:

a) Organização e tratamento bibliométrico: importação dos registros bibliográficos para o Vantage Point e padronização de termos relativos à nomes de instituições: filtros normalizadores; criação de listas para visualização dos dados; a organização e tratamento bibliométrico dos registros coletados utilizando os softwares Vantage Point e MS Excel para elaboração da etapa seguinte.

b) Representações gráficas: exportações das listas para o software Microsoft Excel e elaboração de figuras para apresentação e análise dos resultados. Sendo assim, os registros das publicações científicas foram importados no software bibliométrico VantagePoint (versão 5.0). Foi possível realizar agrupamentos e proceder com a criação de listas e de matrizes como base para elaboração dos indicadores. 


\section{Resultados}

A produção da Ufes representada na WoS, nestes dez anos - total de 6.654 textos -, aumentou consideravelmente, já que em 2009 eram 308 artigos e em 2018 foram 1.078. A taxa de crescimento anual foi significativa, com média de $15,12 \%$ ao ano, como mostra a figura 1.

Figura 1 -

Produção científica da Ufes por ano (2009-2018).

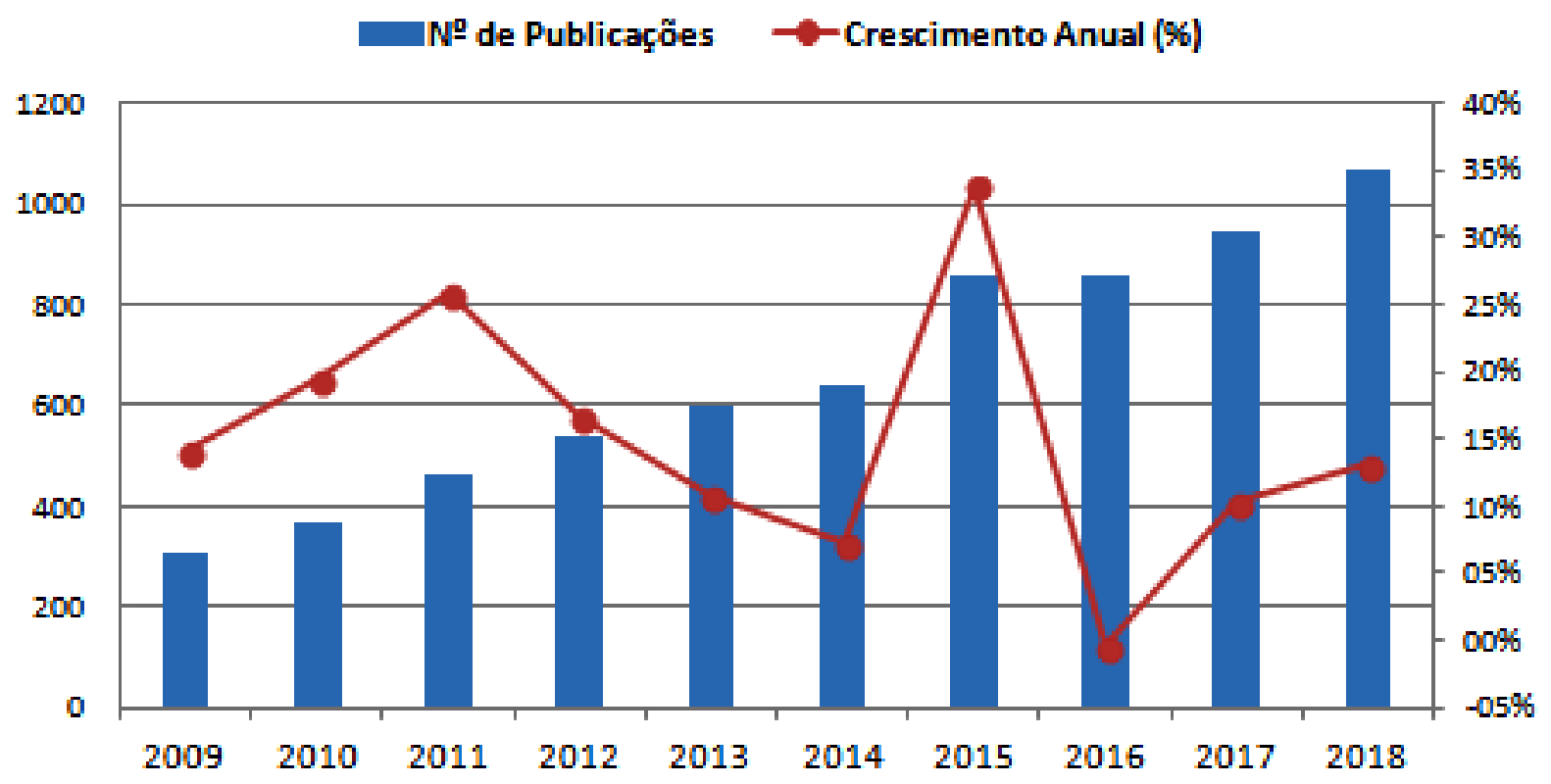

Fonte: dados da pesquisa na WoS (2009-2018).

Em relação à produtividade em geral verificamos, numa década, uma tendência de crescimento sistemático e consistente das publicações na referida base de dados. No ano de 2018 situa-se a maior produção em valores absolutos, com cerca de $16,08 \%$ do total da Ufes.

O idioma principal foi o inglês: $80 \%$ dos textos. Os principais países com os quais se manteve relação foram na produção científica foram: os Estados Unidos 14,6\% das parcerias: 688 textos; a Espanha com 7,7\%: 340 dos itens documentais; a França com 5,2\%: 247 textos; a Inglaterra com 4,5\%: 231 textos; e Portugal, 4,4\%: com 223 textos da produção no período (2009-2018). 
Figura 2 -

Número de publicações da Ufes por país de colaboração (2009-2018).

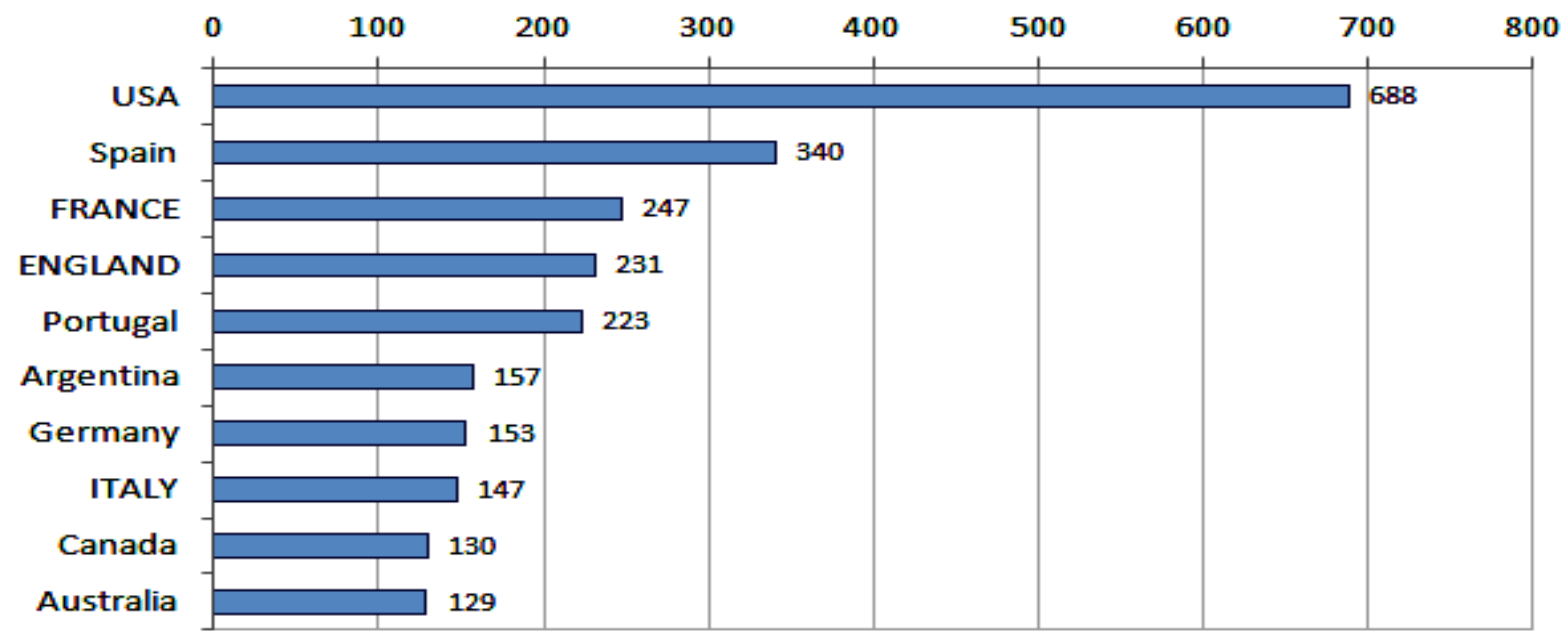

Fonte: dados da pesquisa (WoS).

Para analisar os autores da Ufes mais produtivos na WoS observa-se a contagem de 8.501 registros. Cabe destacar que os dois artigos iniciais nessa base de dados datam o ano de 1973. A figura a seguir apresenta os resultados dos autores que se destacam entre 2009-2018.

Figura 3 -

Número de publicações da Ufes por autor na WoS (2009-2018).

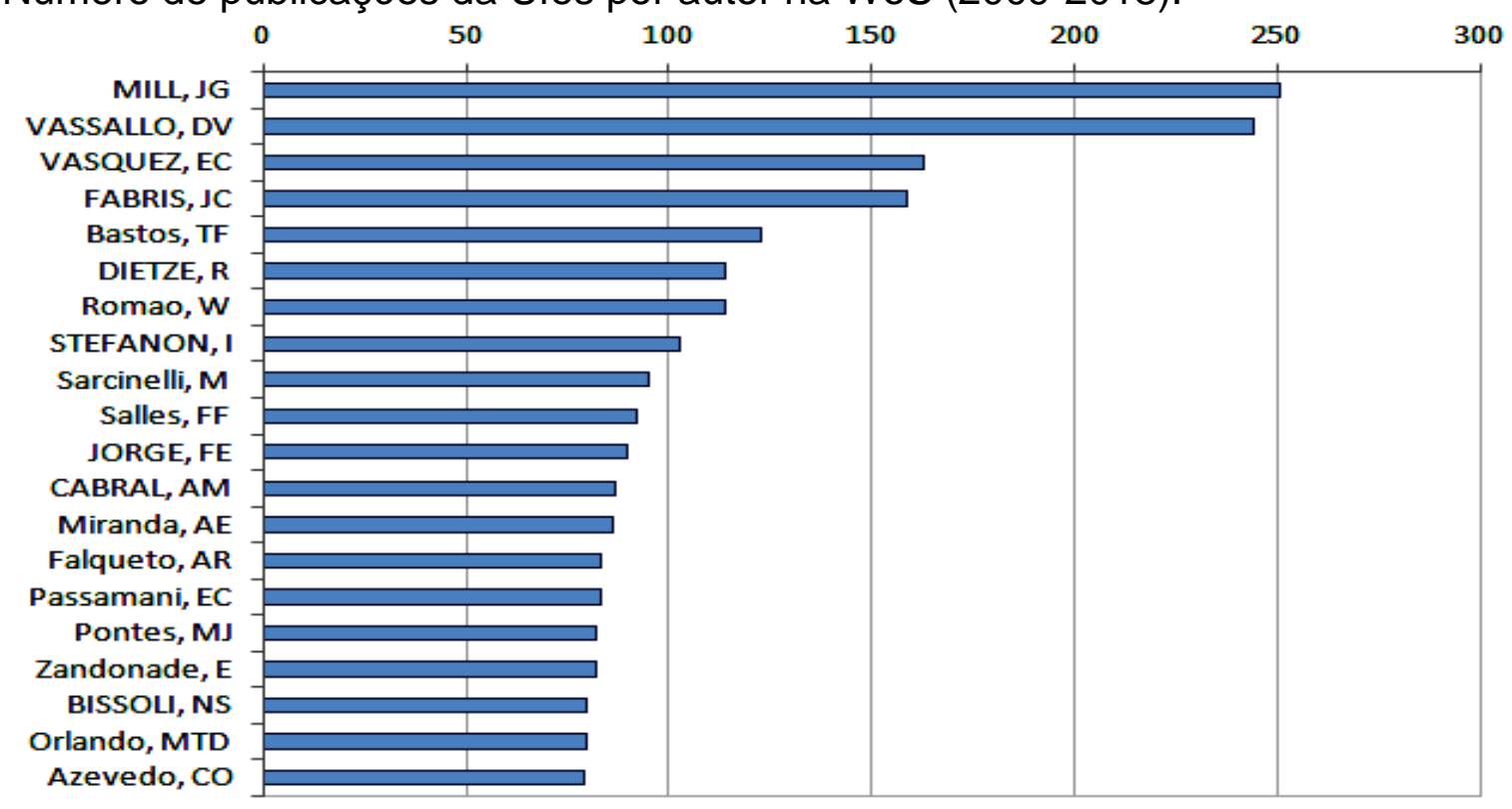

Fonte: dados da recuperados na base de dados.

Pelas medidas de impacto verificou-se que, dos 6.654 artigos da Ufes, representados na WoS entre 2009 e 2018, 4.525 (67,97\%) foram citados. Foi também identificada a manutenção de crescimento das publicações na área de energia e agricultura - figura 4. 
Figura 4 -

Número de publicações da Ufes por área de pesquisa na WoS (2009-2018).

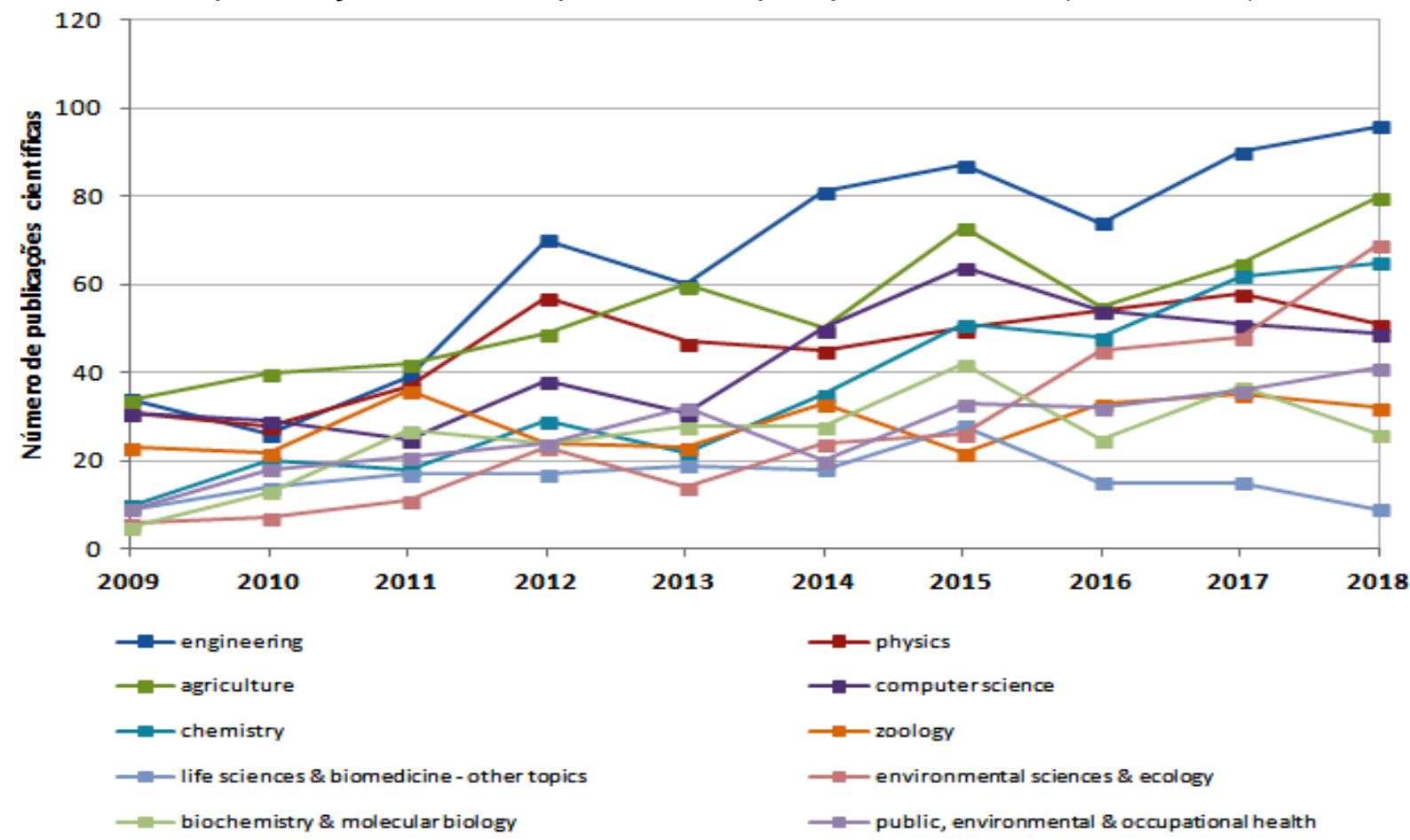

Fonte: dados da pesquisa (WoS).

Os resultados seguem a tendência das demais análises desse estudo, em que as áreas de Psicologia e Energia aparecem com a maior representação na WoS. As dez áreas com maior número de artigos estão dispostos na ilustração a seguir e cabe destacar o salto produtivo na área de Ciências Ambientais e Ecologia.

Figura 5 -

Publicações em colaboração entre autores da IES (Ufes, 2009-2018).

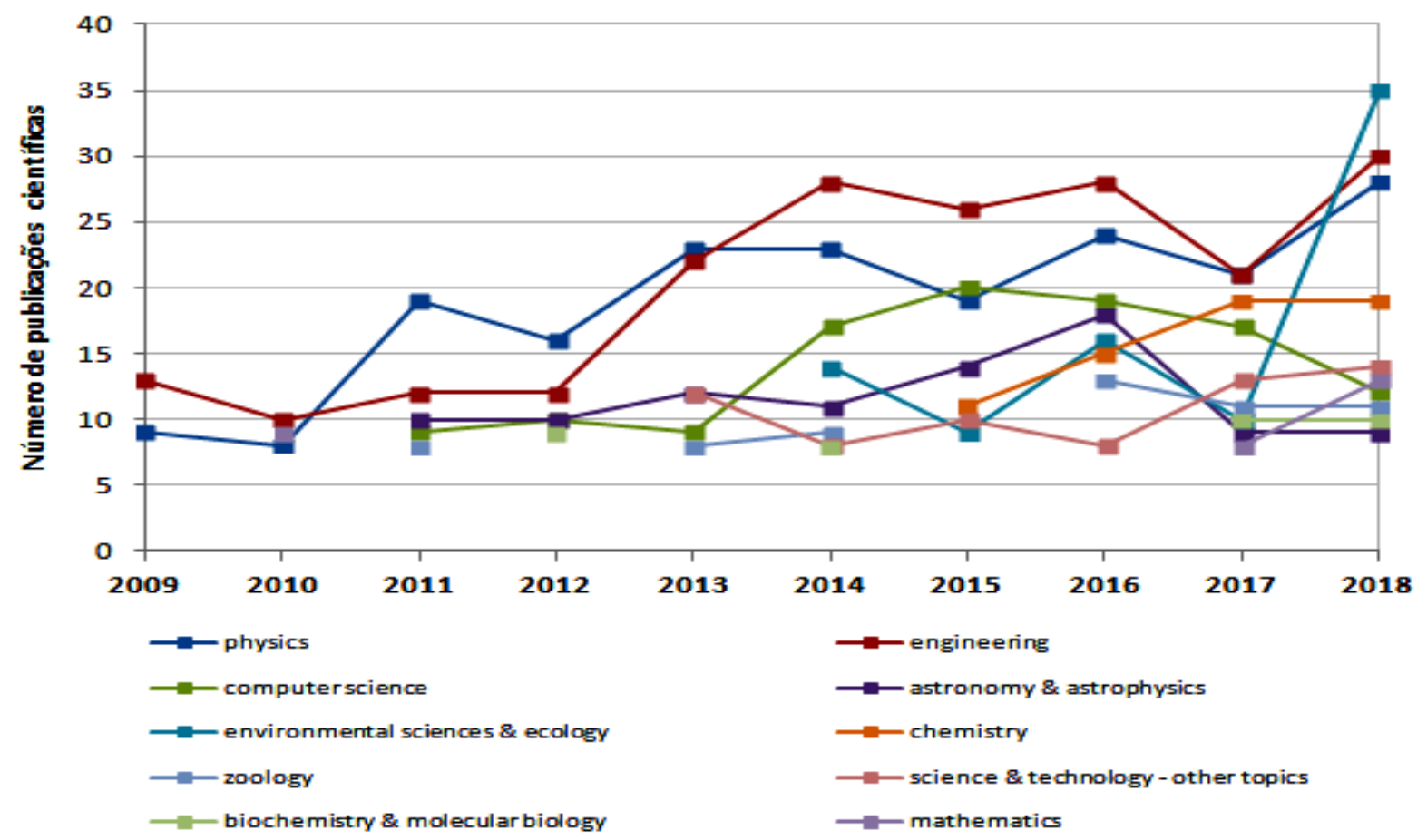

Fonte: dados da pesquisa (WoS).

Regae: Rev. Gest. Aval. Educ. Santa Maria

v. 8

n. 17

Pub. contínua 2019

p. 1-17 
Ainda convém descartar que sete artigos foram altamente citados, com mais de 300 citações cada, sendo três das CET, três das CS e um da área Multidisciplinar. Todos foram escritos no idioma inglês, em coautoria, seis com colaboração internacional e todos publicados em periódicos de alto impacto, tendo, portanto, visibilidade internacional.

Os dados foram tratados e quantificados utilizando-se o software bibliométrico Vantage Point para gerar uma matriz de coocorrência de instituições autoras das publicações. A matriz foi processada nos softwares de análise e representação de redes Ucinet e NetDraw, resultando na rede de colaboradores em publicações apresentada na figura 6.

Figura 6 -

Rede de colaboração entre países a IES (Ufes, 2009-2018).

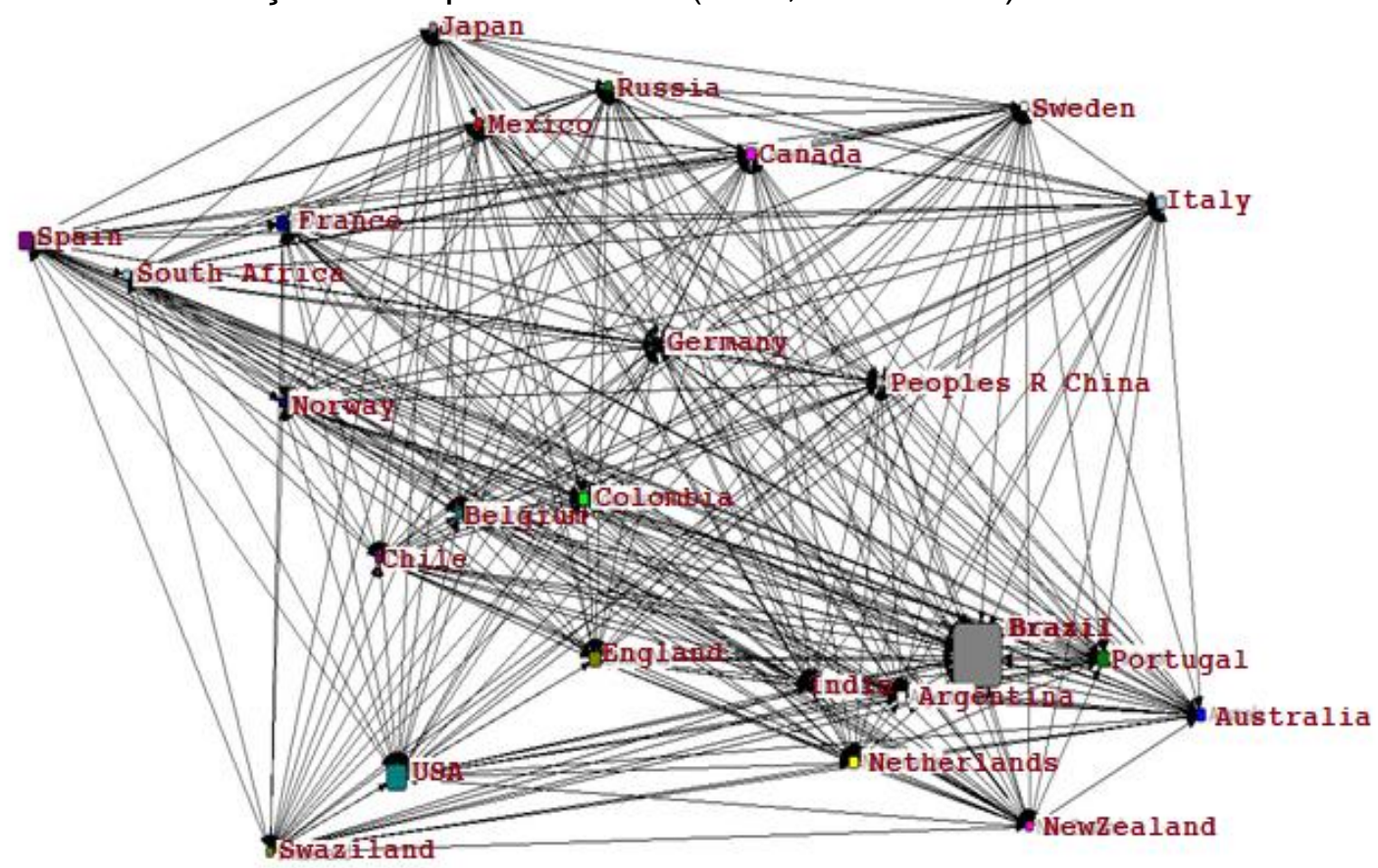

Fonte: dados da pesquisa (WoS).

Em relação à análise sobre colaboração, cabe inferir que professores da Ufes participam de grupos mundiais de pesquisa, que reúnem cientistas e instituições conceituadas na atualidade. Assim, o nível de atividade cooperativa dos pesquisadores entre disciplinas de qualquer nível - autor, instituição, país -, adotando como premissa que muitos autores e grupos compartilhando ideias, podem gerar trabalhos mais qualificados atuando em rede (Mugnaini; Strehl, 2008; Brambilla; Stumpf, 2012).

Cabe à universidade, portanto, incentivar a colaboração e a troca de experiências entre os seus pesquisadores e os de outras instituições e países, em todos os campos, apesar dos padrões diferenciados de produção e de comunicação da ciência, que refletem maneiras diferentes de fazer pesquisa. A ciência, instalada nas universidades, encontrou o locus adequado para seu desenvolvimento e é nesse ambiente que começaram a se formar grupos por especialidades, formando comunidades e 
subcomunidades, de acordo com as especificidades e os interesses em comum (Ziman, 1981). Essa estrutura focal representa a divisão do conhecimento que, por consequência, leva a uma especialização dos saberes em partes sempre mais específicas (Brambilla; Stumpf, 2012).

Em suma, entende-se que comunicação científica existe desde há muitos séculos e com formatos diferentes dos de hoje. Desde as primeiras descobertas cientificas os investigadores sentiram necessidade de divulgá-las e, neste sentido, as universidades têm feito esforços para disponibilizar às suas comunidades acadêmicas bases de dados eletrônicas completas e que vão de encontro às necessidades letivas e de investigação (Fernandes, 2012).

\section{Considerações finais}

Neste estudo foram abordados os resultados principais da pesquisa, que permitiram avaliar a visibilidade da produção científica de autores vinculados à Ufes representados na WoS no período 2009-2018. Nestes dez anos a produção aumentou consideravelmente, de 308 artigos, em 2009, para 1.078 em 2018, sendo as Ciências Agrárias e as Engenharias as áreas com maior índice de atividade.

Pelas medidas de impacto verificou-se que $74,9 \%$ dos artigos da Ufes na WoS já foram citados. Pode-se concluir, portanto, que os artigos são, na maioria, feitos em coautoria, registrados em inglês e em periódicos nacionais e estrangeiros de impacto, sendo esta a produção com maior visibilidade. Além disso, as áreas do conhecimento têm influência sobre o número de citações que os artigos recebem de outros autores.

A análise dos dados revelou padrões e comportamentos da ciência produzida na Ufes e tornou possível a visualização dos núcleos preferenciais de cada área. Uma das principais recomendações diz respeito ao escopo do trabalho, haja vista que há poucos estudos realizados sobre a produção científica de universidades brasileiras. Diante isso é pertinente destacar a declaração do professor Freitas Neto: "as universidades são caras, mas necessárias, por formar a elite intelectual e científica do país. Sem produção científica e tecnológica não podemos almejar qualquer perspectiva de soberania intelectual, econômica e social" (Freitas Neto, 2018, p. 1).

Pretende-se, com esse diagnóstico, dar visibilidade à produção científica da Ufes, mostrando a importância e o impacto do trabalho acadêmico realizado neste sistema científico. Espera-se, também, que outras universidades façam o mesmo com respeito a sua produção, para que se tenha um cenário atual sobre o percurso da produção científica acadêmica brasileira.

A Ufes é referência regional e nacional no ensino superior, como atestam diversas avaliações realizadas, externas e internas, aparecendo nos primeiros lugares entre as instituições de ensino superior do país. O interesse por esses resultados reside não só na descrição exaustiva de um conjunto de indicadores mas, acima de tudo, por permitir a análise da visibilidade alcançada por essa produção. Ainda, pode ter valor para os gestores e para os próprios pesquisadores, por se tratar de uma avaliação objetiva e de uma visão global da atividade investigativa realizada no âmbito da CT\&I. As IES precisam conhecer o comportamento diferenciado de produção científica de cada áreas de conhecimento e campos de saber para adotar políticas que tornem mais visíveis e usáveis essa produção. 


\section{Referências}

ARAÚJO, Uajará Pessoa et al. Trajetória e estado corrente da sociometria brasileira. Redes: Revista hispana para el análisis de redes sociales, v. 28, n. 2, 2017, p. 97-128. Disponível em https://doi.org/10.5565/rev/redes.706. Acesso em 18 fev. 2019.

BARBA, Bruno Maltrás. Los indicadores bibliométricos: fundamentos y aplicación al Análisis de la Ciencia. Gijón: Trea, 2003.

BELLOTTO, Heloisa Liberalli. Universidade e arquivos: perfil, história e convergência. Trans-in-formação, Campinas, v. 1, n. 3, 1989, p. 15-28. Disponível em http://periodicos.puc-campinas.edu.br/seer/index.php/transinfo/article/view/1679. Acesso em 11 mar. 2019.

BELLOTTO, Heloísa Liberalli. Universidade e arquivos: perfil, história e convergência. In: BELLOTTO, Heloísa Liberalli. Arquivo: estudos e reflexões. Belo Horizonte: UFMG, 2014b, p. 64-79. Disponível

em http://periodicos.puccampinas.edu.br/seer/index.php/transinfo/article/view/1679. Acesso em 5 abr. 2019.

BOHRER, Iza Neuza et al. A história das universidades e o despertar do conhecimento. In: JORNADA NACIONAL DA EDUCAÇÃO, 14, 2008. Anais... Santa Maria: Unifra, 2008. Disponível em http://www.unifra.br/eventos/jne2008/Trabalhos/114.pdf. Acesso em 20 abr. 2017.

BORGO, Ivanir Antonio. Ufes: 40 anos de história. Vitoria: Ufes, 1995.

BRAMBILLA, Sônia Domingues Santos; STUMPF, Ida Regina Chittó. Produção científica da Ufrgs representada na Web of Science (2000-2009). Perspect. ciênc. inf., Belo Horizonte, v. 17, n. 3, 2012, p. 34-50.

CUNHA, Luiz Antônio. Ensino superior e universidade no Brasil. In: LOPES, Eliane Marta Teixeira; FARIA FILHO, Luciano Mendes; VEIGA, Cynthia Greive (org.). 500 anos de Educação no Brasil. Belo Horizonte: Autêntica, 2000. p. 151-204.

FERNANDES, Alberto Nuno Oliveira. $O$ uso de revistas eletrónicas por docentes/investigadores da faculdade de letras da universidade do porto: estudo bibliométrico. Páginas A\&B, Arquivos e Bibliotecas (Portugal), n. 10, 2012. Disponível em https://ojs.letras.up.pt/index.php/paginasaeb/article/view/588/562. Acesso em 27 maio 2019.

SUGIMOTO, Luiz. 100 anos da reforma de Córdoba. Jornal Unicamp, Campinas, 12 jun. 2018. Disponível em https://www.unicamp.br/unicamp/ju/noticias/2018/06/12/100-anos-dareforma-de-cordoba. Acesso em 17 jul. 2019.

LEITE, Denise; MOROSINI, Marília. Universidade no Brasil: a ideia e a prática. R. bras. Est. pedag., Brasília, v. 73, n. 174, 1992, p. 242-254. Disponível em http://rbep.inep.gov.br/index.php/RBEP/article/viewFile/450/455. Acesso em 18 jun. 2019.

MEADOWS, Arthur Jack. A comunicação científica. Brasília: Briquet de Lemos/Livros, 1999.

MUELLER, Suzana Pinheiro Machado. A publicação da ciência: áreas científicas e seus canais preferenciais. DataGramaZero: Revista de Ciência da Informação, v. 6, n. 1, 2005. Disponível em http://inseer.ibict.br/ancib/index.php/tpbci/article/view/11/9. Acesso em 19 fev. 2019. 
MUGNAINI, Rogério; STREHL, Letícia. Recuperação e impacto da produção científica na era google: uma análise comparativa entre o google acadêmico e a web of science. Encontros Bibli, Florianópolis, 2008, p. 92-105. Disponível em https://doi.org/10.5007/1518-2924.2008v13nesp1p92. Acesso em 27 maio 2019.

SCHWARTZMAN, Simon. Um espaço para a ciência: a formação da comunidade científica no Brasil. Brasília: Ministério da Ciência e Tecnologia, 2001.

STUMPF, Ida Regina Chitto. Passado e futuro das revistas científicas. Ciência da Informação, Brasília, v. 25, n. 3, 1996, p. 383-386.

UNIVERSIDADE FEDERAL DO ESPÍRITO SANTO (org.). UFES, 60 anos. Vitória: Ufes, 2014.

UNIVERSIDADE FEDERAL DO ESPÍRITO SANTO. Departamento de Administração dos Órgãos Colegiados Superiores. Resolução n. 08/2014, de 10 de abril de 2014. Vitória: Ufes, 2014b. Disponível em http://www.daocs.ufes.br/resolu\%C3\%A7\%C3\%B5es-de2014-cun. Acesso em 3 de ago. 2019.

UNIVERSIDADE FEDERAL DO ESPÍRITO SANTO. Departamento de Administração dos Órgãos Colegiados Superiores. Resolução n. 27/2014, de 26 de junho de 2014. Vitória: Ufes, 2014c. Disponível em http://www.daocs.ufes.br/resolu\%C3\%A7\%C3\%B5es-de2014-cun. Acesso em 3 de ago. 2019.

UNIVERSIDADE FEDERAL DO ESPÍRITO SANTO. Estatuto da Universidade Federal do Espírito Santo Brasil. Vitória: Ufes, 2012b. Disponível em http://www.ufes.br/estatuto-daufes. Acesso em 22 jul. de 2019.

UNIVERSIDADE FEDERAL DO ESPÍRITO SANTO. Sobre a Ufes: a instituição. Vitória: Ufes, 2019a. Disponível em http://www.ufes.br/instituição. Acesso em 22 jul. 2019.

UNIVERSIDADE FEDERAL DO ESPÍRITO SANTO. Sobre a Ufes: como funciona a Ufes. Vitória: Ufes, 2019b. Disponível em http://www.ufes.br/como-funciona-ufes. Acesso em 22 jul. 2019.

UNIVERSIDADE FEDERAL DO ESPÍRITO SANTO. Universidade Federal do Espírito Santo. Vitória: Ufes, 2012.

VANZ, Samile Andréa de Souza; STUMPF, Ida Regina Chittó. Procedimentos e ferramentas aplicados aos estudos bibliométricos. Informação \& Sociedade: Estudos, João Pessoa, v. 20, n. 2, 2010, p. 67-75.

ZIMAN, John. A força do conhecimento. Belo Horizonte: Itatiaia, 1981.

ZIMBA, Horácio Francisco; MUELLER, Suzana Pinheiro Machado. Colaboração internacional e visibilidade científica de países em desenvolvimento:o caso da pesquisa na área de medicina veterinária em Moçambique. Informação \& Sociedade: Estudos, v. 14, n. 1, 2004. Disponível em http://hdl.handle.net/20.500.11959/brapci/92272. Acesso em 8 mar. 2019.

URBIZAGASTEGUI, Ruben Alvarado; RESTREPO-ARANGO, Cristina. Crescimento da literatura sobre bibliometria, informetria e cientometria no Brasil. Revista Ibero-Americana de Ciência da Informação, v. 10, n. 1, 2017, p. 6-31. 
Rosa da Penha Ferreira da Costa é doutora em Ciência da Informação e coordenadora do Mestrado em Ciência da Informação e do Núcleo de Preservação da Informação da Ufes.

Orcid: https://orcid.org/0000-0002-5379-1323.

Endereço: Avenida Fernando Ferrari, 514 - 29075-910 - Vitória - ES - Brasil.

E-mail: rosapenha2012@gmail.com.

Marcelo Calderari Miguel é pós-graduado em Matemática Financeira e Estatística e estudante de Arquivologia na Ufes.

Orcid: http://orcid.org/0000-0002-7876-9392.

Endereço: Avenida Fernando Ferrari, 514 - 29075-910 - Vitória - ES - Brasil.

E-mail: marcelocalderari@yahoo.com.br.

Recebido em 29 de julho de 2019.

Aceito em 9 de setembro de 2019.

(c) $\oplus_{\mathrm{BY}}$ 